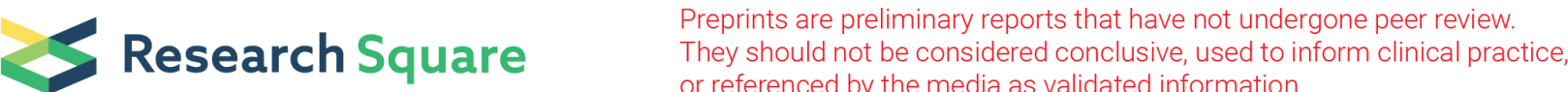 or referenced by the media as validated information.
}

\section{N-Myc and STAT Interactor is a Novel Biomarker of Severity in Community-Acquired Pneumonia: A Cohort Study}

\section{Wanying Zhang}

Zhejiang University School of Medicine Second Affiliated Hospital

\section{Hui Zhou}

Zhejiang University School of Medicine Second Affiliated Hospital

\section{Mengyuan Cen}

Zhejiang University School of Medicine Second Affiliated Hospital

\section{Wei Ouyang}

Zhejiang University School of Medicine Second Affiliated Hospital

Jie Chen

Zhejiang University School of Medicine Second Affiliated Hospital

\section{Lexin Xia}

Zhejiang University School of Medicine Second Affiliated Hospital

Xiuhui Lin

Zhejiang University School of Medicine Second Affiliated Hospital

Jinliang Liu

Zhejiang University School of Medicine Second Affiliated Hospital

\section{Teng He}

Zhejiang University School of Medicine Second Affiliated Hospital

\section{Feng Xu ( $\nabla$ xufeng99@zju.edu.cn )}

Zhejiang University School of Medicine Second Affiliated Hospital https://orcid.org/0000-0001-5764-6628

\section{Research Article}

Keywords: N-myc and STAT interactor, community-acquired pneumonia, biomarker, mortality

Posted Date: March 10th, 2021

DOI: https://doi.org/10.21203/rs.3.rs-283643/v1

License: (c) (i) This work is licensed under a Creative Commons Attribution 4.0 International License. Read Full License 


\section{Abstract}

Background: Community-acquired pneumonia (CAP) is among the deadliest infectious diseases. Severe CAP progresses rapidly and has a high mortality rate which requires early detection. N-myc and STAT interactor (NMI) is a novel biomarker involved in inflammatory diseases.

Methods: Prospective observational analysis of patients with CAP. The NMI levels in serum of 394 CAP patients on admission were measured to assess the ability of NMI to assess clinical outcomes. The NMI levels in bronchoalveolar lavage fluid (BALF) of 37 CAP patients were also tested to identify severe and non-severe group.

Results: The serum NMI levels in CAP patients with poor clinical outcomes were significantly higher $(P<0.001)$ than those without outcomes. The AUC of NMI to predict mortality was 0.91 (95\% Cl: $0.86-0.96$ ), and that to predict ICU admission was 0.92 (95\% Cl: 0.88-0.97), significantly higher than that of other biomarkers such as PCT and CRP. The AUC of the new score systems (N-PSI and N-CURB65) to predict outcomes were significantly higher than the original score systems. Furthermore, the AUC of NMI in BALF was 0.93 (95\% Cl: $0.86-1.00)$ for predicting severe CAP.

Conclusions: $\mathrm{NMI}$ is a novel effective biomarker for predicting CAP severity.

\section{Introduction}

Community-acquired pneumonia (CAP) remains to be one of the most deadly infectious diseases [1]. 44\% of CAP patients experience severe sepsis as a complication [2, 3], and mortality of severe CAP patients can reach $20-25 \%$ who need vasopressor support and require admission to the intensive care unit (ICU) [4].

The omission of severe CAP patients often leads to a delay in appropriate therapeutic management of patients [5], thus increasing the length of stay (LOS) and mortality [6]. To date, the pneumonia severity index (PSI) and the British Thoracic Society (BTS) CURB65 score are the most commonly-used severity scoring tools for CAP [7]. The PSI stratifies patients into five classes based on age, the presence of coexisting disease, abnormal physical findings (RR $\geq 30$ /min or temperature $\geq 40^{\circ} \mathrm{C}$ ), and abnormal laboratory findings $(\mathrm{pH}<7.35$, blood urea nitrogen concentration $\geq$ $11 \mathrm{mmol} / \mathrm{L}$, and sodium concentration $<130 \mathrm{mmol} / \mathrm{l}$ ), and etc. to predict 30-day mortality. CAP with a PSI score $\geq \mathrm{IV}$ is considered high-risk [8]. The CURB65 score is the recommended severity assessment strategy both in the community and hospital by the 2009 updated version of BTS guidelines [9]. CURB65 score system includes five indicators: altered mentation, blood urea $>7.0 \mathrm{mmol} / \mathrm{l}$, respiratory rate $\geq 30 / \mathrm{min}$, systolic blood pressure $<90 \mathrm{mmHg}$ or diastolic blood pressure $\leq 60 \mathrm{mmHg}$, and age $\geq 65$ years old. Each of the indicators counts for one point, and scores $\geq 2$ are classified as moderate-severe pneumonia [10]. Biomarkers are also widely used to assess the severity of pneumonia,including procalcitonin (PCT), C-reactive protein (CRP), and proadrenomedullin (proADM) [11-13]. In most studies of CAP severity evaluation tools, 30-day mortality is considered to be the most frequently used outcome [7]. However, some young severe CAP patients with good health in the past may have a low mortality but a high risk of ICU admission[14], so both the 30-day mortality and ICU admission should be considered when evaluating the efficacy of CAP severity tools. The length of stay (LOS) was also related to the severity of CAP, as patients with high PSI grade had a longer LOS than those with low PSI grade [15].

$\mathrm{N}$-myc and STAT interactor (NMI), a binding partner of N-myc and c-Myc oncogenes, acts as a transcriptional regulator in multiple signaling pathways in the nucleus $[16,17]$. It has been linked to tumor growth and progression as well as participating with macrophages in the inflammatory response $[18,19]$. NMI plays a key role in proinflammatory cytokine interleukin (IL)-32ع-mediated apoptosis by inhibiting Wnt/ $\beta$-catenin signaling and activating cmyc-mediated apoptosis to regulate the host defense against pathogens such as Mycobacterium tuberculosis[20]. 
Severe acute respiratory syndrome coronavirus (SARS-CoV) protein 6 enhanced the degradation of NMI through the ubiquitin proteasome pathway to inhibit the downstream interferon (IFN) signal transduction pathway and promoted the survival of SARS-CoV in host cells [21]. Recently, a study showed that by activating nuclear factor-kB through Tolllike receptor (TLR) 4 as a damage associated molecular pattern, NMI activated macrophages and released proinflammatory cytokines [18]. The serum levels of NMI were also increased in patients who died from severe inflammation [18]. These results indicate that NMI is involved in the pathogenesis of the inflammatory response, but the relationship between NMI levels and CAP severity still remains unknown.

In this study, we explored whether the NMI level can be used as a novel biomarker to stratify CAP severity and predict the prognosis of severe CAP.

\section{Methods}

\section{Participants}

The study was carried out at the Second Affiliated Hospital of Zhejiang University (Hangzhou, Zhejiang, China) and was approved by the ethics committee.

The serum of 394 adult patients with CAP and BALF from 37 adult CAP patients and 23 controls were collected from January 2019 to November 2020 in the Second Affiliated Hospital of Zhejiang University. Controls were defined as patients undergoing bronchoscopy due to lung tumors, pulmonary sarcoidosis and other non-infectious diseases. The exclusive criteria was as follows: 1) patients under 18 years old; 2) patients with autoimmune diseases, such as systemic lupus erythematosus, rheumatoid arthritis, etc.; 3) patients who received chemotherapy drugs, immunosuppressive agents or hormones for a long time; 4) patients who underwent bone marrow or peripheral blood stem cell transplantation; 5) patients with HIV infection. CAP and severe-CAP were diagnosed according to the 2007 Infectious Diseases Society of America (IDSA)/American Thoracic Society (ATS) guidelines [22].

\section{Methods Of Measurement}

Peripheral venous blood was collected before antibiotics treatment within 24 hours after admission to the hospital and BALF was gathered at the first bronchoscopy examination. Blood samples were kept at room temperature for $4 \mathrm{~h}$ and centrifuged at $1000 \mathrm{rpm}$ for $20 \mathrm{~min}$ at $4^{\circ} \mathrm{C}$. Serum and BALF were aliquoted and stored at $-80^{\circ} \mathrm{C}$. The concentrations of NMI in serum were measured using ELISA kits (CSB-EL015893HU, CUSABIO) according to the manufacturer's protocols.

\section{Clinical Data Collection}

Clinical data were extracted from the electronic medical records of each patient. The PSI and CURB65 score, PCT and CRP concentration, white blood cell (WBC), neutrophil count and neutrophil count percentage (NCP) on the day of admission, death and ICU admission within 30 days and LOS were recorded in adult CAP patients.

\section{Statistical analysis}

First, we assessed the differences of serum NMI and other parameters (PCT, CRP, WBC, neutrophil count and NCP) between groups suffered poor outcomes and groups without these outcomes. We then used receiver operating characteristic curve (ROC) to evaluate the area under the curve (AUC) of NMI and other indexes for predicting 
occurrence of 30-day mortality and ICU admission. We also reported sensitivity, specificity, and Youden index (sensitivity + specificity -1 ) of these biomarkers. We further analyzed differences in the incidence of clinical outcomes among various NMI cutoffs by Kaplan-Meier survival curves. After that, we validated the correlation of NMI with LOS and other biomarkers using Spearman correlation coefficient. Besides, we evaluated the diversities of NMI concentrations in different levels of the PSI and CURB65 score and then compared effectiveness of new severity score system (N-PSI and N-CURB65 score system) with the original score system for predicting clinical outcomes. Finally, we compared the levels of NMI in BALF between severe and non-severe groups of CAP patients.

All results were analyzed by SPSS-16 and MedCalc software. Measurement data and enumeration data were expressed by median quartile spacing and frequency (percentage), respectively. All data were represented by scatter plots. Horizontal lines showed the lower quartile, median, and upper quartile. Mann-Whitney U test and Kruskal-Wallis $\mathrm{H}$ test were used to compare differences between two or more groups, and Nemenyi test was used for pairwise comparisons after multiple groups. Log-rank test was used to verify differences among Kaplan-Meier curves. We used method of DeLong et al. and Z-statistics to determine the difference of AUC between two and multiple ROC curves. The optimum cut-off values were calculated according to the maximum Youden index [23]. $P$ value $<0.05$ was regarded as statistically significant.

\section{Results}

\section{Clinical characteristics}

The Hangzhou cohort consisted of 394 CAP patients with a median age of $40(31-67)$ and $59.6 \%$ of them were male.

$16.75 \%$ of patients were classified as high-risk according to the PSI score (IV-V grade), while $10.66 \%$ were classified as high-risk patients based on CURB65 score ( $\geq 3$ points).

$7.87 \%$ of the patients died within 30 days of admission, and $11.68 \%$ were admitted to the ICU. The characteristics of all selected patients were shown in Table 1. 
Table 1

Baseline characteristics and outcome of CAP patients in Hangzhou cohort.

\begin{tabular}{|ll|}
\hline Characteristics & \multicolumn{1}{|l|}{ Patients with CAP $(\mathbf{n}=394)$} \\
\hline Demographic characteristics \\
\hline Age (years) & $40(31-67)$ \\
\hline Males & $235(59.64)$ \\
\hline PSI class & $328(83.25)$ \\
\hline I-III & $34(8.63)$ \\
\hline IV & $32(8.12)$ \\
\hline V & \\
\hline CURB65 score class & $323(81.98)$ \\
\hline $0-1$ & $29(7.36)$ \\
\hline 2 \\
\hline $3-5$ & $42(10.66)$ \\
\hline Clinical outcomes & \\
\hline $30-$ day mortality & $31(7.87)$ \\
\hline ICU admission & $46(11.68)$ \\
\hline Data are presented as median (interquartile range) or $n(\%)$ \\
\hline
\end{tabular}

\section{Predictive values of NMI for clinical outcomes in patients with CAP}

30-day mortality and ICU admission were set as clinical outcomes representing the severity of CAP patients. Levels of NMI, CRP, PCT, neutrophil count and NCP were significantly increased in the group with poor clinical outcomes, but no significant difference was found in WBC (Fig. 1, 2). The AUC of NMI to predict mortality was 0.91 (95\% Cl: 0.86-0.96) with a cut-off value of $55.48 \mathrm{pg} / \mathrm{ml}$, much higher than that of PCT $(0.79$ (95\% Cl: $0.70-0.88), P<0.01), \mathrm{CRP}(0.78$ (95\% Cl: 0.69-0.87), $P<0.01)$, WBC (0.59 (95\% Cl: 0.47-0.71), $P<0.001)$, neutrophil count (0.65 (95\% Cl: 0.54-0.75), $P<0.001)$, and NCP (0.78 (95\% Cl: 0.70-0.86), $P<0.01)$ (Fig. 1, Table 2). The AUC of NMI to predict ICU admission was 0.92 (95\% Cl: 0.88-0.97) (Fig. 2, Table 2). The Youden index for predicting 30-day mortality and ICU admission by NMI was $72.22 \%$ and $75.18 \%$, respectively, both higher than other indicators (Table 2 ). 
Table 2

Diagnostic performance analysis of CAP patients in Hangzhou cohort.

\begin{tabular}{|c|c|c|c|c|c|c|c|c|}
\hline & Predictic & of mortality & & & Predictio & of ICU admi & sion & \\
\hline & $\begin{array}{l}\text { AUC } \\
(95 \% \\
\text { Cl) }\end{array}$ & $\begin{array}{l}\text { Sensitivity } \\
(\%)\end{array}$ & $\begin{array}{l}\text { Specificity } \\
(\%)\end{array}$ & $\begin{array}{l}\text { Youden } \\
\text { index } \\
(\%)\end{array}$ & $\begin{array}{l}\text { AUC } \\
(95 \% \\
\text { Cl) }\end{array}$ & $\begin{array}{l}\text { Sensitivity } \\
(\%)\end{array}$ & $\begin{array}{l}\text { Specificity } \\
(\%)\end{array}$ & $\begin{array}{l}\text { Youden } \\
\text { index } \\
\text { (\%) }\end{array}$ \\
\hline NMI & 0.91 & 87.10 & 85.12 & 72.22 & 0.92 & 86.96 & 88.22 & 75.18 \\
\hline & $\begin{array}{l}(0.86- \\
0.96)\end{array}$ & & & & $\begin{array}{l}(0.88- \\
0.97)\end{array}$ & & & \\
\hline PCT & $0.79 * *$ & 64.52 & 86.61 & 51.13 & $0.80^{\star \star *}$ & 65.32 & 87.76 & 53.08 \\
\hline (119/1III) & $\begin{array}{l}(0.70- \\
0.88)\end{array}$ & & & & $\begin{array}{l}(0.72- \\
0.88)\end{array}$ & & & \\
\hline CRP (mg/l) & $0.78^{\star \star}$ & 61.29 & 75.12 & 36.41 & $0.76 * \star \star$ & 56.51 & 85.30 & 41.81 \\
\hline & $\begin{array}{l}(0.69- \\
0.87)\end{array}$ & & & & $\begin{array}{l}(0.69- \\
0.84)\end{array}$ & & & \\
\hline WBC & $0.59 \star \star \star$ & 35.48 & 84.81 & 20.29 & $0.58^{\star \star \star \star}$ & 32.61 & 90.20 & 22.81 \\
\hline$(10 \% / 1)$ & $\begin{array}{l}(0.47- \\
0.71)\end{array}$ & & & & $\begin{array}{l}(0.48- \\
0.69)\end{array}$ & & & \\
\hline Neutrophils & $0.65^{\star \star \star}$ & 80.65 & 45.73 & 26.38 & $0.63^{\star \star \star *}$ & 36.96 & 87.05 & 24.01 \\
\hline$(1007)$ & $\begin{array}{l}(0.54- \\
0.75)\end{array}$ & & & & $\begin{array}{l}(0.53- \\
0.72)\end{array}$ & & & \\
\hline NCP (\%) & $0.78^{\star \star}$ & 90.32 & 58.84 & 49.16 & $0.73^{\star \star \star \star}$ & 69.57 & 72.33 & 41.90 \\
\hline & $\begin{array}{l}(0.70- \\
0.86)\end{array}$ & & & & $\begin{array}{l}(0.65- \\
0.82)\end{array}$ & & & \\
\hline PSI & $0.85^{\& \&}$ & 88.43 & 77.42 & 65.85 & $0.84^{\& \& \&}$ & 65.22 & 89.66 & 54.88 \\
\hline & $\begin{array}{l}(0.77- \\
0.94)\end{array}$ & & & & $\begin{array}{l}(0.77- \\
0.90)\end{array}$ & & & \\
\hline N-PSI & 0.91 & 86.78 & 83.87 & 70.65 & 0.90 & 91.30 & 74.71 & 66.01 \\
\hline & $\begin{array}{l}(0.86- \\
0.96)\end{array}$ & & & & $\begin{array}{l}(0.86- \\
0.94)\end{array}$ & & & \\
\hline $\begin{array}{l}\text { CURB65 } \\
\text { score }\end{array}$ & $0.86^{\# \#}$ & 83.87 & 87.60 & 71.47 & $0.84^{\# \# \#}$ & 73.91 & 89.37 & 63.28 \\
\hline & $\begin{array}{l}(0.77- \\
0.95)\end{array}$ & & & & $\begin{array}{l}(0.76- \\
0.91)\end{array}$ & & & \\
\hline N-CURB65 & 0.93 & 83.87 & 92.84 & 76.71 & 0.92 & 80.43 & 86.49 & 66.92 \\
\hline & $\begin{array}{l}(0.89- \\
0.97)\end{array}$ & & & & $\begin{array}{l}(0.89- \\
0.96)\end{array}$ & & & \\
\hline $\begin{array}{l}\text { N-CURB65: } \\
\text { compared W } \\
\text { method of D } \\
\text { method of D }\end{array}$ & $\begin{array}{l}\text { bined N } \\
\text { NMl usi } \\
\text { ong et al } \\
\text { ong et al }\end{array}$ & $\begin{array}{l}\text { /CURB65 } \\
\text { the z statis } \\
\#: P<0.01 \text {, }\end{array}$ & $\begin{array}{l}\text { e; N-PSI: c } \\
\text { \&\&: } P<0.0 \\
: P<0.001\end{array}$ & $\begin{array}{l}\text { bined NM } \\
\& \& \&: P<0.0 \\
\text { mpared } \mathrm{W}\end{array}$ & $\begin{array}{l}\text { *: } P<C \\
\text { mpare } \\
\text { CURB6 }\end{array}$ & $\begin{array}{l}* * *: P<0 . \\
\text { th N-PSI } \\
\text { tore using }\end{array}$ & $\begin{array}{l}\star \star \star: P<0.00 \\
g \text { the nonpo } \\
\text { nonparam }\end{array}$ & $\begin{array}{l}\text { metric } \\
\text { ic }\end{array}$ \\
\hline
\end{tabular}


In addition, we analyzed differences in the incidence of clinical outcomes across different NMI cutoffs by KaplanMeier survival curves. The risk of 30-day mortality (Fig. 3A) and ICU admission (Fig. 3B) increased as the level of NMI rose $(P<0.001)$. The 30 -day mortality rate $(37.5 \%)$ and ICU admission rate $(62.5 \%)$ were the highest in patients with $\mathrm{NMI}>100 \mathrm{pg} / \mathrm{ml}$, while the 30 -day mortality rate and ICU admission rate were $0.4 \%$ and $0.8 \%$ in patients with $\mathrm{NMI}<25$ $\mathrm{pg} / \mathrm{ml}$, respectively. Taken together, the efficiency of NMI in predicting the mortality and ICU admission of CAP was better than the commonly used clinical markers, and NMI levels were positively correlated with rates of adverse clinical outcomes.

\section{Correlation Of Nmi With Los And Other Indicators}

To validate the relationship between serum NMI levels and current severity assessment indicators of CAP, we evaluated the correlation of NMI with LOS, PCT, CRP, WBC, neutrophil count and NCP using Spearman correlation coefficient. As shown in Fig. 4, NMI was significantly correlated with LOS (correlation coefficient $r=0.4202, P<0.001$ ), and also with PCT, CRP, WBC, neutrophils and NCP (Fig. 4).

\section{Serum NMI levels of CAP patients with different risk stratifications}

To compare the differences in serum NMI levels of CAP patients with different risk stratifications, we tested the NMI levels of patients with different classes of the PSI and CURB65 scores (Fig. 5). Results showed that NMI levels gradually increased from the low-risk group to high-risk group in both PSI and CURB65 score system $(P<0.001)$, except that there were no differences between the PSI scores of IV and V (Fig. 5A). Besides, we evaluated the corrective effect of NMI on the original severity system in predicting clinical outcomes. AUC of the new score system (the N-PSI and N-CURB65 score) for predicting mortality (0.91 (95\% Cl: $0.86-0.96)$ and 0.93 (95\% Cl: 0.89-0.97), respectively) was significantly increased than that of the previous scoring system, and AUC of new score system for ICU admission (0.90 (95\% Cl: 0.86-0.94) and 0.92 (95\% Cl: 0.89-0.96), respectively) was also higher than before (Fig. 6, Table 2).

\section{Nmi Levels In Balf}

To further evaluate the broad applicability of NMI prediction on CAP severity, we also measured the levels of NMI in BALF of CAP patients and analyzed the difference of NMI concentration between severe group and non-severe group. A total of 37 CAP patients were tested, 11 of whom were severe CAP. The concentration of NMI in severe CAP patients was significantly higher than that in non-severe CAP group $(P<0.01)$, and the AUC for predicting severe CAP was 0.93 (95\% Cl: 0.86-1.00) (Fig. 7). The result suggests that NMI in BALF was also associated with the severity of CAP patients.

\section{Discussion}

The early stratification of CAP patients will help optimize hospital resources and formulate a diagnosis and treatment plan [24]. NMI is a regulator involved in various inflammatory diseases by participating with macrophages in the inflammatory response. In this study, we tested NMI levels in patients with CAP in two separate cohorts to explore the role of NMI in predicting severity of CAP. We measured NMI levels in both serum and BALF of CAP patients and analyzed its correlation with clinical outcomes (30-day mortality and ICU admission). We compared the efficiency of NMI levels in predicting CAP severity with other classical CAP severity score systems and biomarkers. Our results showed that NMI is a novel biomarker reflecting the severity of CAP patients. 
Many parameters have been studied and widely applied to assess the severity of CAP patients, among which the PSI and CURB65 score are the most recommended in international guidelines [7]. The PSI score can accurately predict the 30-day mortality rate, however, the complexity of its 20 variables limits its clinical application. As simple as CURB-65 is, it underestimates the potential severity of young patients and mistakes elderly CAP patients as severe CAP patients [7]. The expanded-CURB-65 improved the recognition of patients with severe CAP compared with CUBR-65 to some extent, but it didn't involve specific biomarkers [25]. Our results showed that it's not sufficient enough to predict 30-day mortality or ICU admission based on the PSI or CURB-65 score alone, and the addition of specific biomarkers may further improve the predictive ability of these scores [26]. A more convenient, highly efficient, and earlier recognition score system is urgently needed (32).

Some biomarkers were showed to be related to CAP, such as PCT, CRP, proADM, and c-terminal vasopressin (copeptin) $[12,13,27,28]$, and they play an important role in estimating the severity, treatment, discontinuation, and etiology in the management of CAP patients $[29,30]$. PCT can guide antibiotic treatment or discontinuation in lower respiratory tract infection [29]. However, PCT can't improve the predictive ability of the PSI/CURB65 score [31, 32] and is insufficient to distinguish bacterial from viral infection [33]. CRP shows only moderate predictive values for mortality of CAP $[13,34,35]$. Some new biomarkers like proADM and copeptin may be useful to infer mortality and severity of CAP, but further verification is needed $[7,36]$. Although there are some biomarkers such as CRP that can distinguish bacterial pneumonia, their value in predicting the severity of CAP in the early stage is limited $[37,38]$.

Compared with the biomarkers mentioned above, our study revealed that NMI concentration at admission is superior in assessing the severity and risk of death of CAP. First, a higher comprehensive efficiency of NMI than CRP and PCT was found in predicting 30-day mortality and ICU admission in CAP patients. Second, the serum NMI level of patients with severe CAP on the day of admission was significantly higher than that of non-severe CAP patients, suggesting that NMI is an early indicator of the severity of CAP. Finally, the AUC was significantly increased after adding NMI to PSI and CURB65 score both for 30-day mortality and ICU admission. All of these indicate the superior potential value of $\mathrm{NMI}$ in the clinical application of CAP.

Previous studies have already shown that NMI is associated with various inflammatory diseases $[18,19,39,40]$. Xiahou et al. found that serum NMI levels in human significantly increased in sepsis patients and were associated with mortality [18]. Wu et al. showed that NMI expression in human lung A549 cells was upregulated after H3N2 SIV infection [40]. NMI levels also elevated in serum and liver tissue of patients with hepatitis B virus-related acute-tochronic liver failure and the concentrations of NMI decreased when in convalescent stage of disease [19]. Our current results showed that the expression of NMI in both serum and BALF was significantly increased in CAP and that NMI levels were positively correlated with mortality and ICU admission. Together, the results indicated that NMI expression in both serum and local tissue were increased in infectious diseases, and might be related to the prognosis of the disease. Interference with NMI expression presumably relieves inflammation and improves prognosis as experiments confirmed that NMI and IFP35 knockout sepsis mice had reduced inflammation and mortality [18]. Wang et al. also found that the apoptosis induced by foot and mouth disease virus was significantly inhibited after silencing NMI expression [41]. Therefore, NMI can possibly be used not only as a predictor of the severity, but also as a therapeutic target of CAP patients.

Hitherto, the mechanisms of NMI participating in inflammatory response have been explored. Wang et al. found that after Sendai virus infection, NMI overexpression mice exerted antiviral effects by limiting the overproduction of type I IFN [42]. Similarly, Hu et al. found that overexpression of NMI reduced the replication of prototype foamy virus [43]. Nevertheless, Cheng et al. found that 293T cells infected with SARS-CoV promoted the NMI ubiquitin-dependent protein degradation [21]. Xiahou et al further elucidated that NMI acted as a proinflammatory 
damage associated molecular pattern in mice with sepsis and promoted macrophages to release inflammatory factors TNF and IL- 6 by activating TLR4 signaling [18]. These evidences indicated that NMI was involved in the process of infectious diseases. However, the mechanisms of NMI involved in the pathogenesis of bacteria and other pathogens need further elucidation.

\section{Conclusion}

In this cohort study, we tested the NMI levels in serum and BALF of CAP patients and found that NMI acted as a novel predictive biomarker for the 30-day mortality and ICU admission of CAP, bringing a foreseeable future for early risk stratification and accurate decision-making.

\section{Abbreviations}

AUC area under the curve

BALF bronchoalveolar lavage fluid

CAP community-acquired pneumonia

CRP C-reactive protein

ICU intense care unit

LOS length of stay

NCP neutrophil count percentage

NMI N-myc and STAT interactor

PCT procalcitonin

ROC receiver operating characteristic

WBC white blood cell;

\section{Declarations}

\section{Acknowledgements}

Not applicable

\section{Author's Contributions:}

WZ and FX designed the study; WZ, HZ, MC, JC and LX collected the specimens and clinical data; WZ, MC, WO and TH Determined and analysed the NMI content; WZ drafted the manuscript; HZ, LX and FX revised the manuscript; JL provide statistical expertise. All authors read and approved the final manuscript.

\section{Funding}


The work was supported by NSFC Grant 81970004

\section{Availability of data and materials}

The data used and analyzed during the current study are available from the corresponding author on reasonable request.

\section{Ethics approval and consent to participate}

The prospective study was approved by Ethics Committee of the Second Affiliated Hospital, Zhejiang University School of Medicine (2020-344). The informed consent of the patient and/or close relatives was not required because samples collected were the remaining blood and bronchoalveolar lavage fluid from the Clinical Laboratory.

\section{Consent for publication}

Not applicable.

\section{Competing interests}

Zhejiang University has submitted a provisional patent application for the NMI-associated CAP severity prediction model reported in this manuscript. F.X. and W.Z. are named as inventors on the provisional patent application.

\section{References}

1. Global, regional, and national age-sex specific mortality for 264 causes of death, 1980-2016: a systematic analysis for the Global Burden of Disease Study 2016. Lancet 2017, 390(10100):1151-1210.

2. Angus DC, Linde-Zwirble WT, Lidicker J, Clermont G, Carcillo J, Pinsky MR. Epidemiology of severe sepsis in the United States: analysis of incidence, outcome, and associated costs of care. Crit Care Med. 2001;29(7):1303-10.

3. Ewig S, Ruiz M, Mensa J, Marcos MA, Martinez JA, Arancibia F, Niederman MS, Torres A. Severe communityacquired pneumonia. Assessment of severity criteria. Am J Respir Crit Care Med. 1998;158(4):1102-8.

4. Scicluna BP, Klein Klouwenberg PM, van Vught LA, Wiewel MA, Ong DS, Zwinderman AH, Franitza M, Toliat MR, Nürnberg P, Hoogendijk AJ, et al. A molecular biomarker to diagnose community-acquired pneumonia on intensive care unit admission. Am J Respir Crit Care Med. 2015;192(7):826-35.

5. Wunderink RG, Waterer GW. Clinical practice. Community-acquired pneumonia. N Engl J Med. 2014;370(6):54351.

6. Waterer GW, Kessler LA, Wunderink RG. Delayed administration of antibiotics and atypical presentation in community-acquired pneumonia. Chest. 2006;130(1):11-5.

7. Chalmers JD, Rutherford J. Can we use severity assessment tools to increase outpatient management of community-acquired pneumonia? Eur J Intern Med. 2012;23(5):398-406.

8. Fine MJ, Auble TE, Yealy DM, Hanusa BH, Weissfeld LA, Singer DE, Coley CM, Marrie TJ, Kapoor WN. A prediction rule to identify low-risk patients with community-acquired pneumonia. New Engl J Med. 1997;336(4):243-50.

9. Lim WS, Baudouin SV, George RC, Hill AT, Jamieson C, Le Jeune I, Macfarlane JT, Read RC, Roberts HJ, Levy ML, et al. BTS guidelines for the management of community acquired pneumonia in adults: update 2009. Thorax. 2009;64(Suppl 3):iii1-55.

10. Grudzinska FS, Aldridge K, Hughes S, Nightingale P, Parekh D, Bangash M, Dancer R, Patel J, Sapey E, Thickett DR, et al. Early identification of severe community-acquired pneumonia: a retrospective observational study. BMJ 
Open Respir Res. 2019;6(1):e000438.

11. Huang DT, Angus DC, Kellum JA, Pugh NA, Weissfeld LA, Struck J, Delude RL, Rosengart MR, Yealy DM. Midregional proadrenomedullin as a prognostic tool in community-acquired pneumonia. Chest. 2009;136(3):823-31.

12. Schuetz P, Suter-Widmer I, Chaudri A, Christ-Crain M, Zimmerli W, Mueller B. Prognostic value of procalcitonin in community-acquired pneumonia. Eur RespiratoryJ. 2011;37(2):384-92.

13. Chalmers JD, Singanayagam A, Hill AT. C-reactive protein is an independent predictor of severity in communityacquired pneumonia. Am J Med. 2008;121(3):219-25.

14. Brito V, Niederman MS. Predicting mortality in the elderly with community-acquired pneumonia: should we design a new car or set a new 'speed limit'. Thorax. 2010;65(11):944-5.

15. Cabre M, Bolivar I, Pera G, Pallares R. Factors influencing length of hospital stay in community-acquired pneumonia: a study in 27 community hospitals. Epidemiol Infect. 2004;132(5):821-9.

16. Zhu M, John S, Berg M, Leonard WJ. Functional association of Nmi with Stat5 and Stat1 in IL-2- and IFNgammamediated signaling. Cell. 1999;96(1):121-30.

17. Bao J, Zervos AS. Isolation and characterization of Nmi, a novel partner of Myc proteins. Oncogene. 1996;12(10):2171-6.

18. Xiahou Z, Wang X, Shen J, Zhu X, Xu F, Hu R, Guo D, Li H, Tian Y, Liu Y, et al. NMI and IFP35 serve as proinflammatory DAMPs during cellular infection and injury. Nat Commun. 2017;8(1):950.

19. Xiong L, Du Y, Zhou T, Du B, Visalath P, Lin L, Bao S, Cai W. N-myc and STAT interactor correlates with severity and prognosis in acute-on-chronic liver failure of hepatitis B virus. J Gastroen Hepatol. 2019;34(10):1800-8.

20. Li Z, Wang Y, Liu X, Xing X, Zhang Y. Interleukin-32 $\varepsilon$ induces caspase-independent apoptosis mediated by N-Myc interactor in macrophages infected with Mycobacterium tuberculosis. FEBS J. 2019;286(3):572-83.

21. Cheng W, Chen S, Li R, Chen Y, Wang M, Guo D. Severe acute respiratory syndrome coronavirus protein 6 mediates ubiquitin-dependent proteosomal degradation of N-Myc (and STAT) interactor. Virol Sin. 2015;30(2):153-61.

22. Mandell LA, Wunderink RG, Anzueto A, Bartlett JG, Campbell GD, Dean NC, Dowell SF, File TM Jr, Musher DM, Niederman MS, et al. Infectious Diseases Society of America/American Thoracic Society consensus guidelines on the management of community-acquired pneumonia in adults. Clin Infect Dis. 2007;44(Suppl 2(Suppl 2):2772.

23. Wang W, Zhou Q, Zhai K, Wang Y, Liu JY, Wang XJ, Wang Z, Zhang JC, Tong ZH, Shi HZ. Diagnostic accuracy of interleukin 27 for tuberculous pleural effusion: two prospective studies and one meta-analysis. Thorax. 2018;73(3):240-7.

24. Frenzen FS, Kutschan U, Meiswinkel N, Schulte-Hubbert B, Ewig S, Kolditz M: Admission lactate predicts poor prognosis independently of the CRB/CURB-65 scores in community-acquired pneumonia. Clin Microbiol Infec 2018, 24(3):306.e301-306.e306.

25. Liu JL, Xu F, Zhou H, Wu XJ, Shi LX, Lu RQ, Farcomeni A, Venditti M, Zhao YL, Luo SY, et al. Expanded CURB-65: a new score system predicts severity of community-acquired pneumonia with superior efficiency. Sci Rep. 2016;6:22911.

26. Gutbier B, Neuhauß AK, Reppe K, Ehrler C, Santel A, Kaufmann J, Scholz M, Weissmann N, Morawietz L, Mitchell TJ, et al. Prognostic and Pathogenic Role of Angiopoietin-1 and - 2 in Pneumonia. Am J Respir Crit Care Med. 2018;198(2):220-31.

27. Christ-Crain M, Morgenthaler NG, Stolz D, Müller C, Bingisser R, Harbarth S, Tamm M, Struck J, Bergmann A, Müller B. Pro-adrenomedullin to predict severity and outcome in community-acquired pneumonia 
[ISRCTN04176397]. Crit Care. 2006;10(3):R96.

28. Mohamed GB, Saed MA, Abdelhakeem AA, Salah K, Saed AM. Predictive value of copeptin as a severity marker of community-acquired pneumonia. Electron Physician. 2017;9(7):4880-5.

29. Schuetz P, Christ-Crain M, Thomann R, Falconnier C, Wolbers M, Widmer I, Neidert S, Fricker T, Blum C, Schild U, et al. Effect of procalcitonin-based guidelines vs standard guidelines on antibiotic use in lower respiratory tract infections: the ProHOSP randomized controlled trial. JAMA. 2009;302(10):1059-66.

30. Müller B, Harbarth S, Stolz D, Bingisser R, Mueller C, Leuppi J, Nusbaumer C, Tamm M, Christ-Crain M. Diagnostic and prognostic accuracy of clinical and laboratory parameters in community-acquired pneumonia. BMC Infect Dis. $2007 ; 7: 10$.

31. Schuetz P, Suter-Widmer I, Chaudri A, Christ-Crain M, Zimmerli W, Mueller B. Prognostic value of procalcitonin in community-acquired pneumonia. Eur Respir J. 2011;37(2):384-92.

32. Menéndez R, Martínez R, Reyes S, Mensa J, Filella X, Marcos MA, Martínez A, Esquinas C, Ramirez P, Torres A. Biomarkers improve mortality prediction by prognostic scales in community-acquired pneumonia. Thorax. 2009;64(7):587.

33. Krüger S, Ewig S, Marre R, Papassotiriou J, Richter K, von Baum H, Suttorp N, Welte T. Procalcitonin predicts patients at low risk of death from community-acquired pneumonia across all CRB-65 classes. Eur Respir J. 2008;31(2):349-55.

34. Menéndez R, Martínez R, Reyes S, Mensa J, Filella X, Marcos MA, Martínez A, Esquinas C, Ramirez P, Torres A. Biomarkers improve mortality prediction by prognostic scales in community-acquired pneumonia. Thorax. 2009;64(7):587-91.

35. Krüger S, Ewig S, Giersdorf S, Hartmann O, Suttorp N, Welte T. Cardiovascular and inflammatory biomarkers to predict short- and long-term survival in community-acquired pneumonia: Results from the German Competence Network, CAPNETZ. Am J Respir Crit Care Med. 2010;182(11):1426-34.

36. Christ-Crain M, Opal SM. Clinical review: the role of biomarkers in the diagnosis and management of communityacquired pneumonia. Crit Care. 2010;14(1):203.

37. Torres A, Ramirez P, Montull B, Menéndez R. Biomarkers and community-acquired pneumonia: tailoring management with biological data. Semin Resp Crit Care Med. 2012;33(3):266-71.

38. Schuetz P, Litke A, Albrich WC, Mueller B. Blood biomarkers for personalized treatment and patient management decisions in community-acquired pneumonia. Curr Opin Infect Dis. 2013;26(2):159-67.

39. Wang JC, Wang YQ, Liu J, Ding L, Zhang QH, Li XQ, Cao H, Tang J, Zheng SJJ. A critical role of N-myc and STAT interactor (Nmi) in foot-and-mouth disease virus (FMDV) 2C-induced apoptosis. Virus Res. 2012;170(1-2):59-65.

40. Wu XP, Wang SY, Yu Y, Zhang JY, Sun ZY, Yan Y, Zhou JY. Subcellular proteomic analysis of human host cells infected with H3N2 swine influenza virus. Proteomics. 2013;13(22):3309-26.

41. Wang JC, Wang YQ, Liu J, Ding L, Zhang QH, Li XQ, Cao H, Tang J, Zheng SJJ. A critical role of N-myc and STAT interactor (Nmi) in foot-and-mouth disease virus (FMDV) 2C-induced apoptosis. Virus Res. 2012;170(1-2):59-65.

42. Wang J, Yang B, Hu Y, Zheng Y, Zhou H, Wang Y, Ma Y, Mao K, Yang L, Lin G, et al: Negative regulation of Nmi on virus-triggered type I IFN production by targeting IRF7. J Immuno/2013, 191(6):3393-3399.

43. Hu XM, Yang W, Liu RK, Geng YQ, Qiao WT, Tan J. N-Myc Interactor Inhibits Prototype Foamy Virus by Sequestering Viral Tas Protein in the Cytoplasm. J Virol. 2014;88(12):7036-44.

\section{Figures}


A

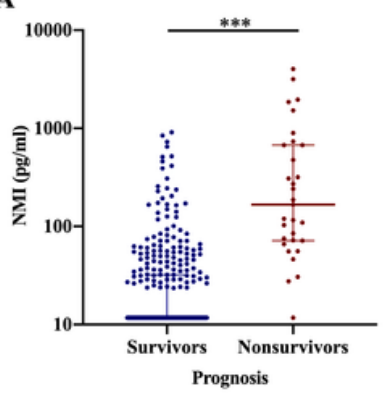

E

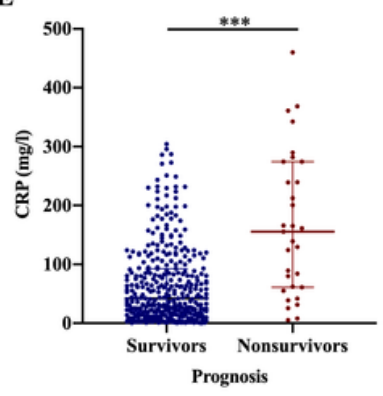

I

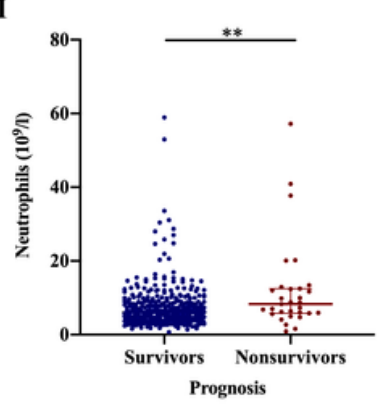

B

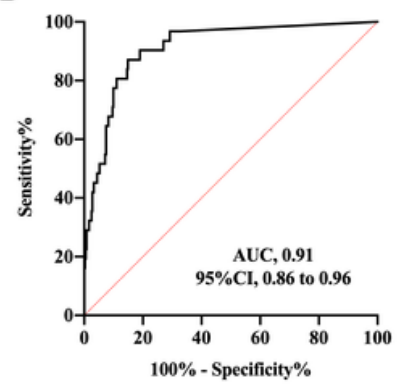

F

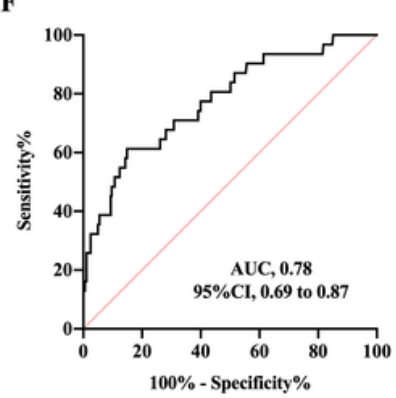

J

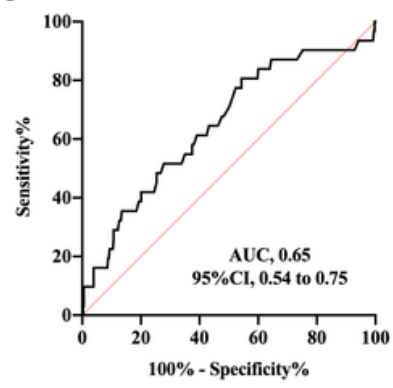

C

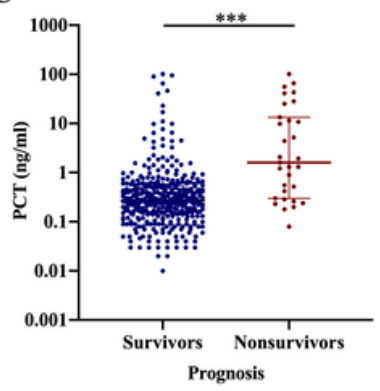

G

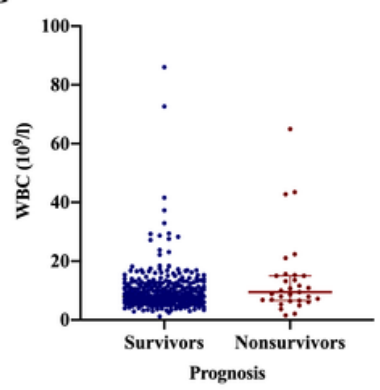

K

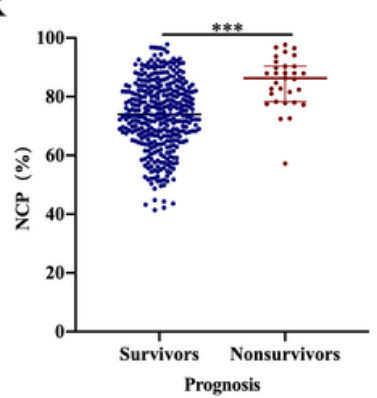

D

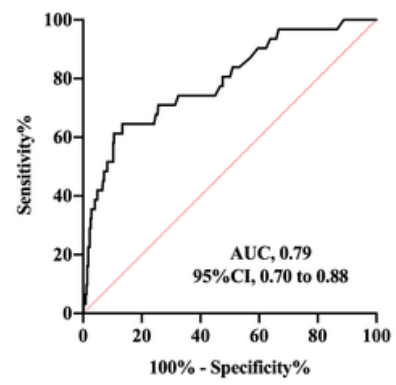

$\mathbf{H}$

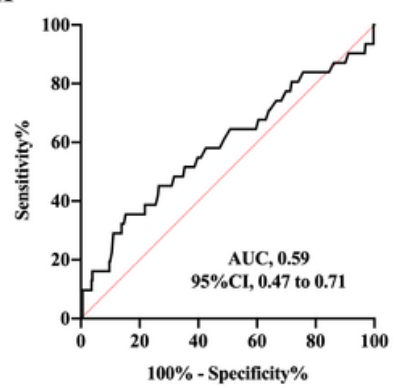

$\mathbf{L}$

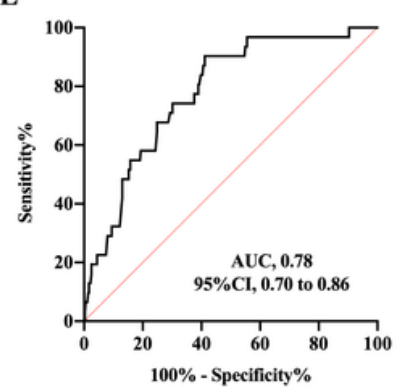

Figure 1

Differences in levels and ROC curve analysis of NMI (A-B), PCT (C-D), CRP (E-F), WBC (G-H), Neutrophils (I-J) and NCP $(\mathrm{K}-\mathrm{L})$ between survivors and non-survivors in CAP patients. Lower and upper lines indicate the 25th and 75th percentiles; middle lines indicate the 50th percentiles. $* *$ : $\mathrm{P}<0.01, * \star \star$ : $\mathrm{P}<0.001$ using the Mann-Whitney U test. 
A

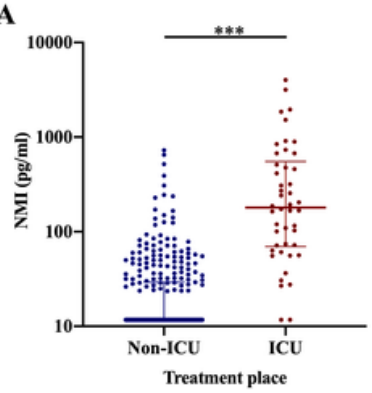

E

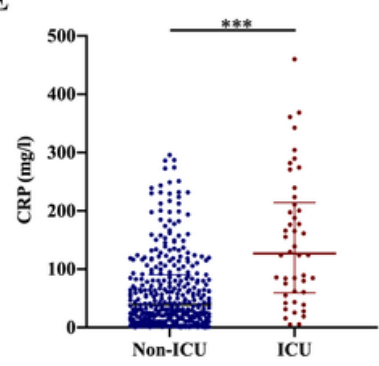

Treatment place

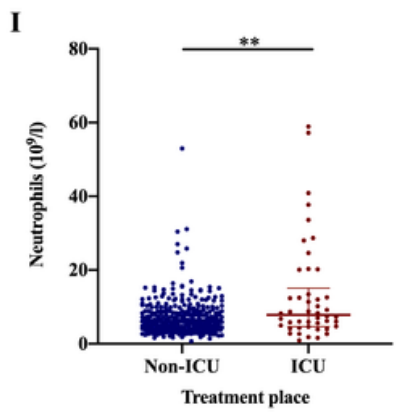

B

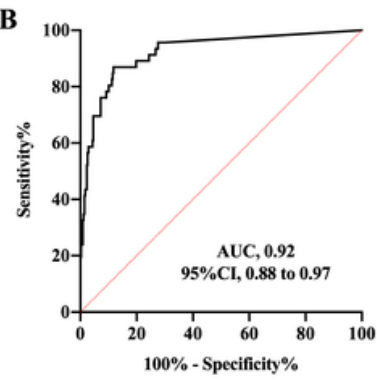

F

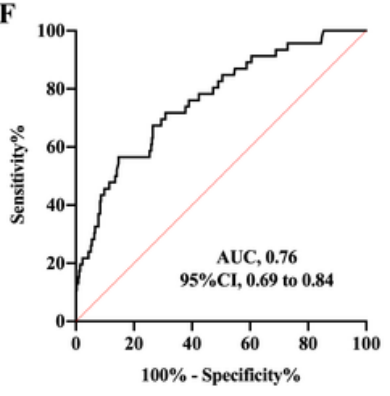

J

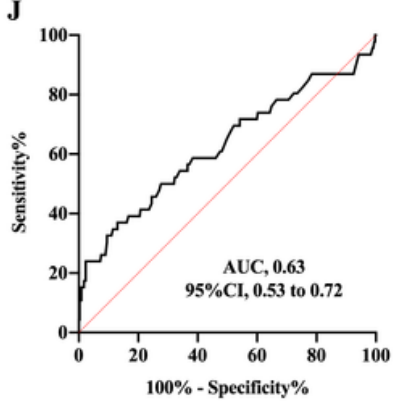

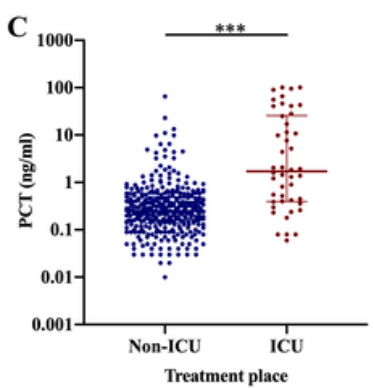

G

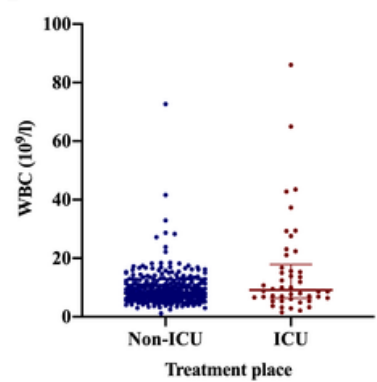

K

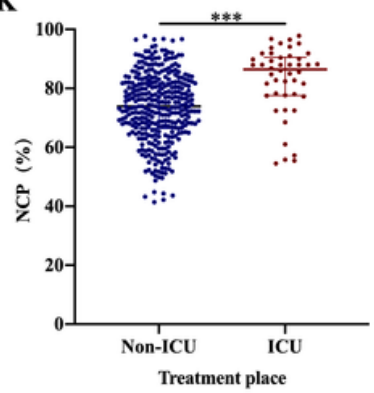

D

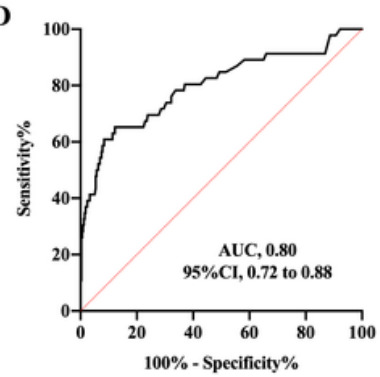

$\mathbf{H}$
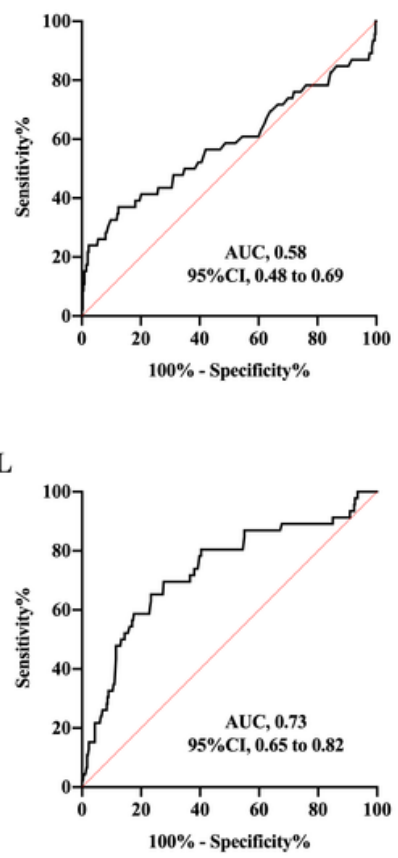

Figure 2

Differences in levels and ROC curve analysis of NMI (A-B), PCT (C-D), CRP (E-F), WBC (G-H), Neutrophils (I-J) and NCP $(\mathrm{K}-\mathrm{L})$ between non-ICU and ICU CAP patients. Lower and upper lines indicate the 25th and 75th percentiles; middle lines indicate the 50th percentiles. **: $\mathrm{P}<0.01$, ***: $\mathrm{P}<0.001$ using the Mann-Whitney $U$ test.
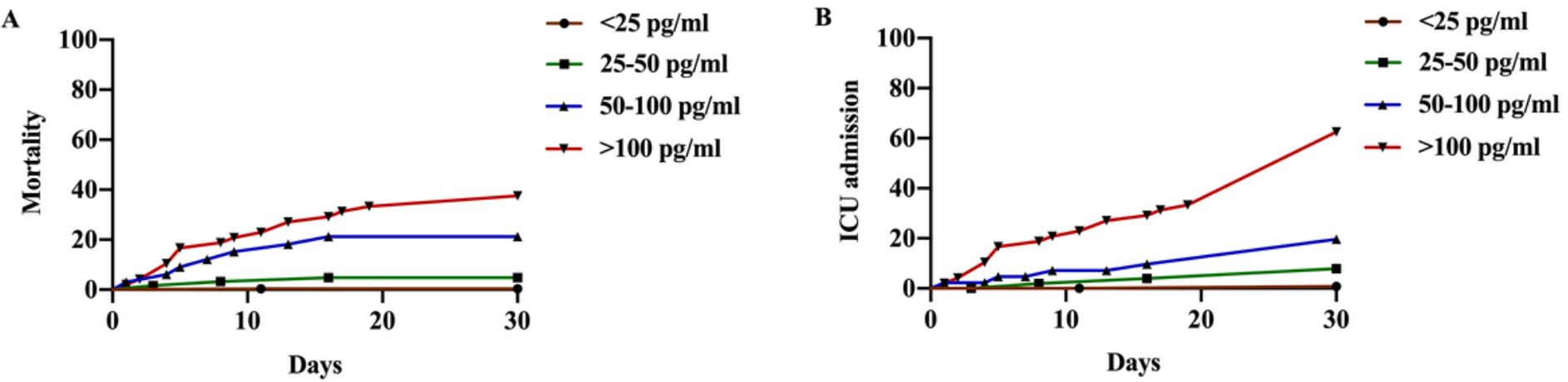

Figure 3

Kaplan-Meier survival curves by NMI cut-offs for 30-day mortality (A) and ICU admission (B) in CAP patients. A significant difference was measured between the four curves $(P<0.001$, log-rank test). 
A

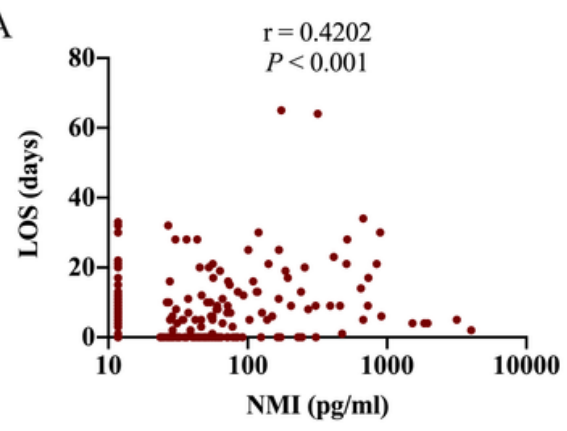

$\mathrm{D}$

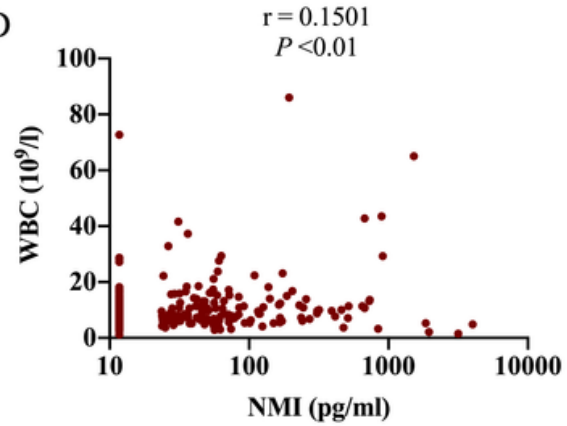

B

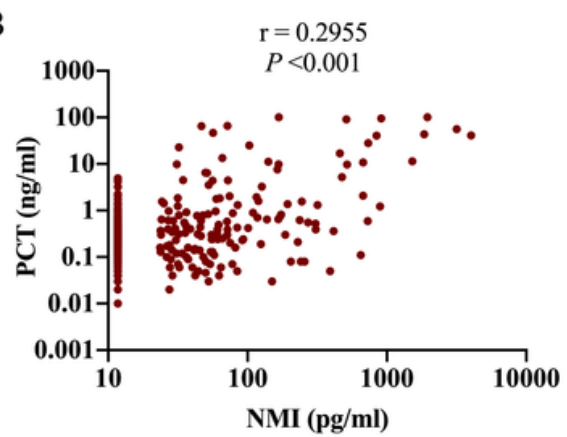

E

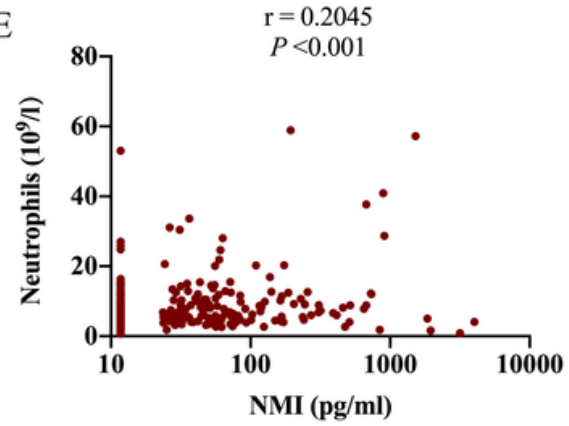

$\mathrm{C}$

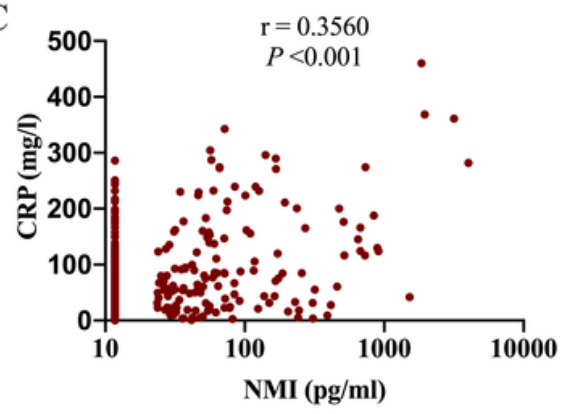

F

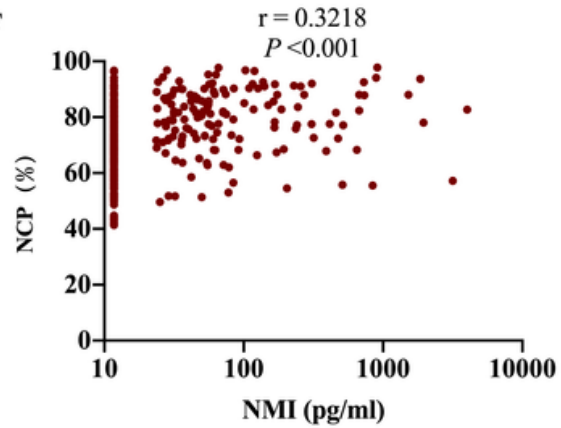

Figure 4

Correlation of NMI levels with LOS (A), PCT (B), CRP (C), WBC (D), Neutrophils (E), and NCP (F) in CAP patients. Correlation was assessed using Spearman correlation coefficient.

A

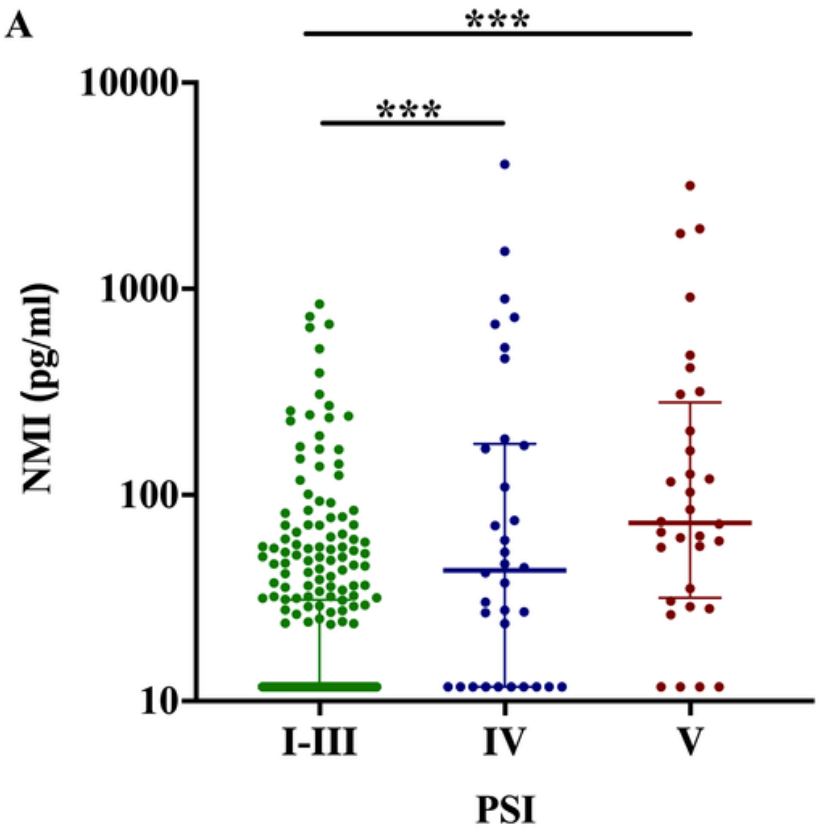

B

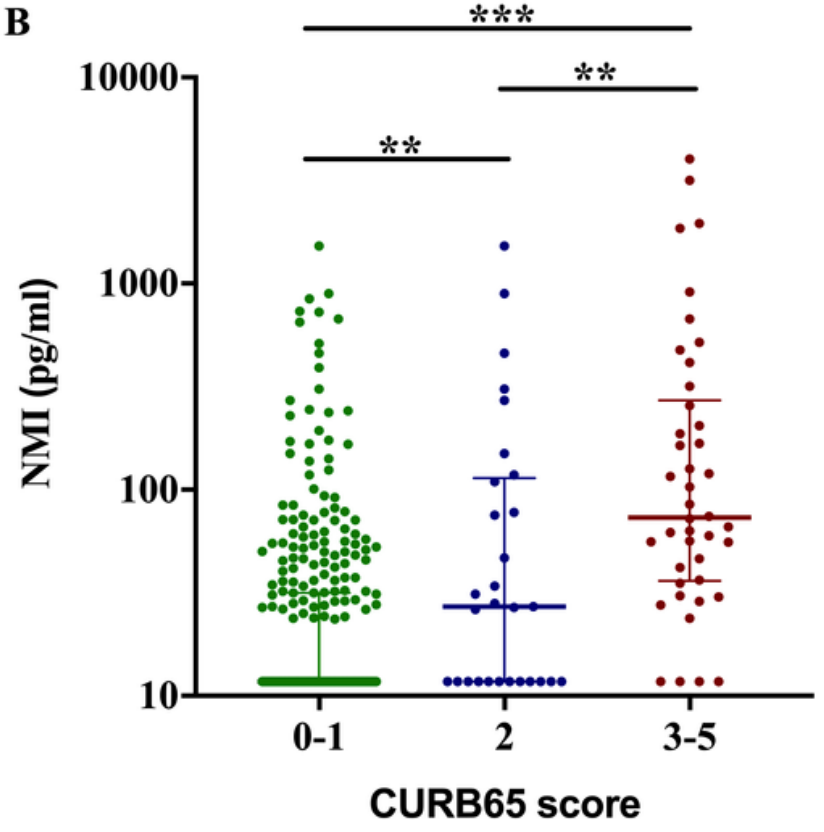

Figure 5

Distribution of NMI levels by PSI class (A) and CURB65 score (B) in CAP patients. Lower and upper lines indicate the 25th and 75th percentiles; middle lines indicate the 50th percentiles. $P<0.001$ in both $A$ and $B$ among the three 
groups by Kruskal-Wallis $\mathrm{H}$ test; $* *$ : $\mathrm{P}<0.01, \star \star *$ : $\mathrm{P}<0.001$ using the Nemenyi test for the comparison in two of multiple samples.

30-day mortality

A



C

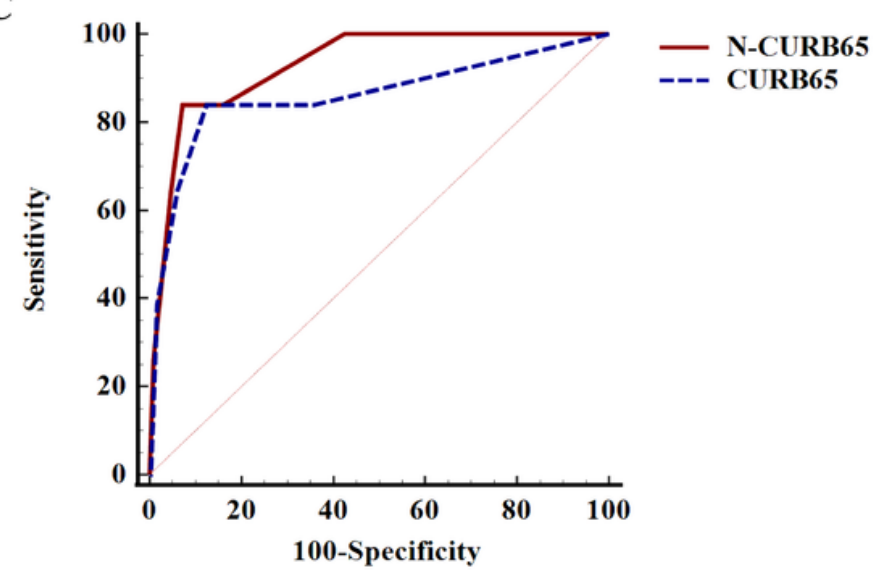

ICU admission

B

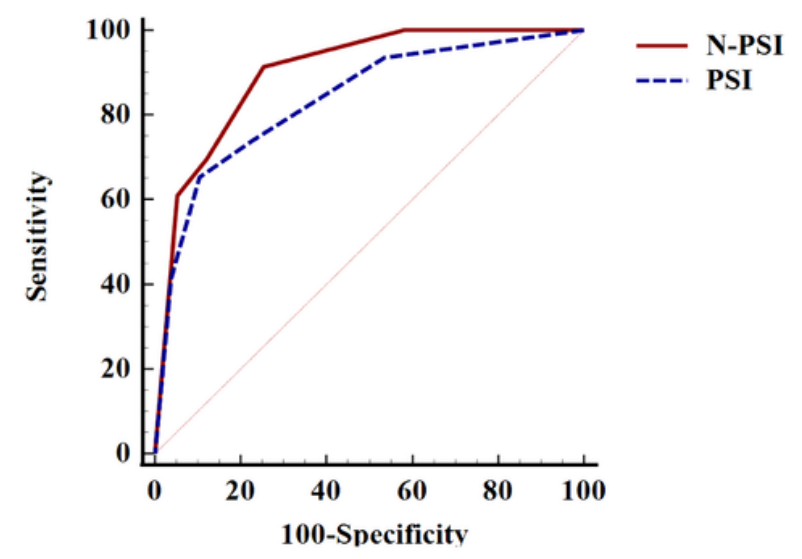

D

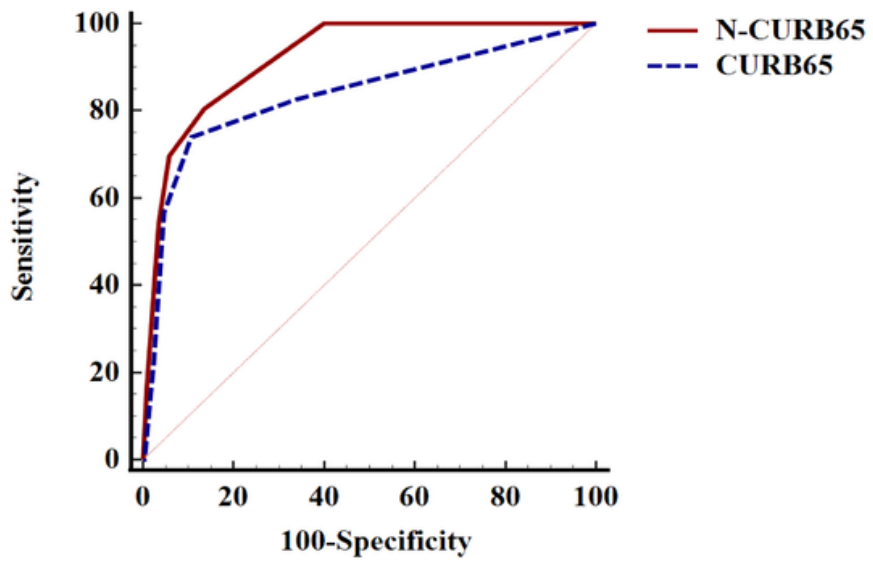

\section{Figure 6}

Corrective effect of $\mathrm{NMI}$ on the original severity system for predicting clinical outcomes in a CAP patients.

Comparison of ROC curves between N-PSI and PSI for predicting 30-day mortality (A) and ICU admission (B). ROC curves were analyzed between N-CURB65 score and CURB65 score for predicting 30-day mortality (C) and ICU admission (D). 

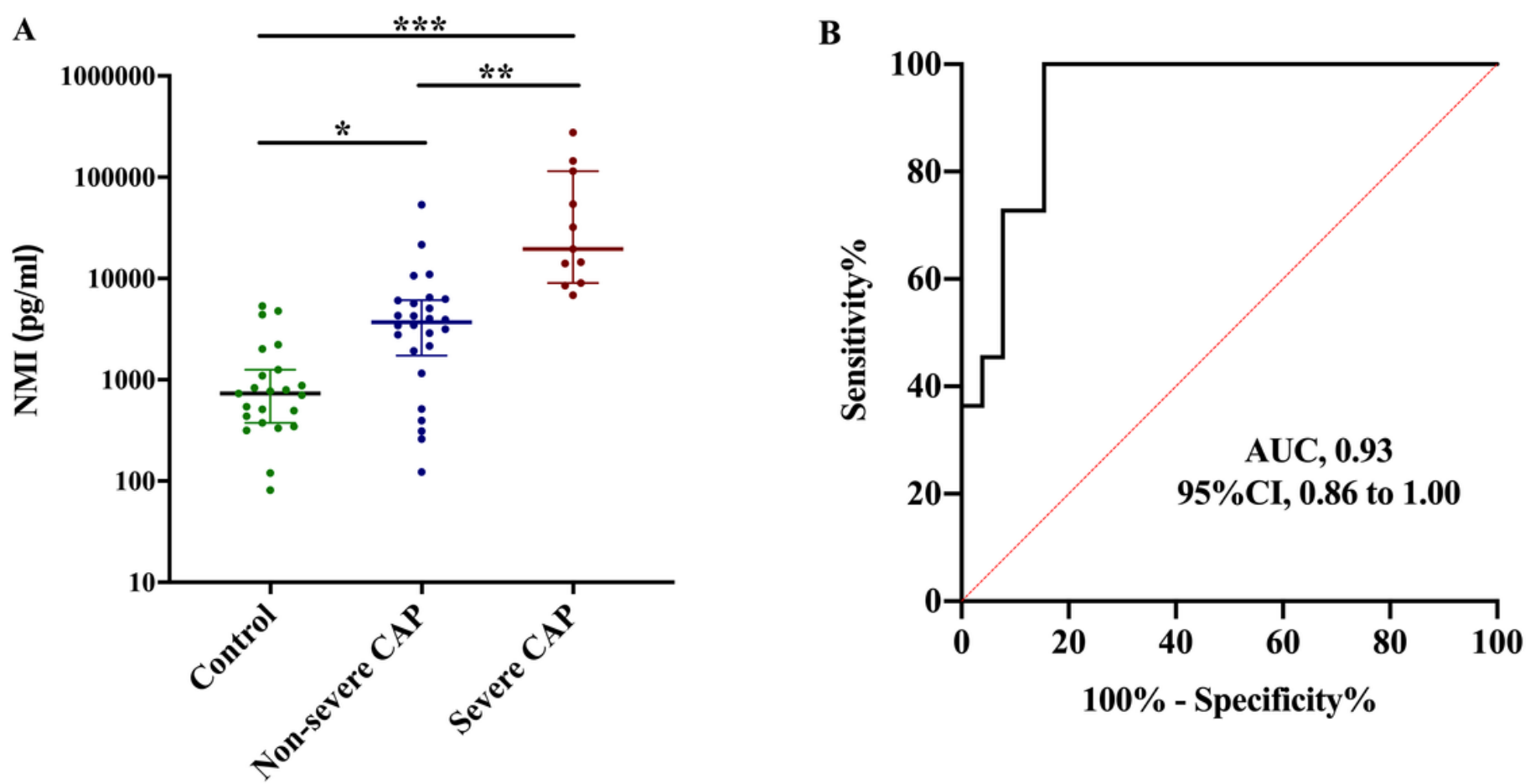

\section{Diagnosis}

\section{Figure 7}

Difference of NMI levels in BALF between severe and non-severe CAP patients (A) and ROC curve analysis of NMI to predict severe CAP $(B)$. Lower and upper lines indicate the 25th and 75th percentiles; middle lines indicate the 50th percentiles. AUC: area under curve; BALF: bronchoalveolar lavage fluid; CAP: community-acquired pneumonia; NMI: Nmyc and STAT interactor; ROC: receiver operating characteristic. $*$ : $P<0.05, * *: P<0.01, * \star *$ : $P<0.001$, using the Nemenyi test for the comparison in two of multiple samples. 